\title{
High-Flow Nasal Cannula Oxygen Therapy Devices
}

\author{
Masaji Nishimura
}

\author{
Introduction \\ Flow Generator \\ Humidifying Device \\ Inspiratory Limb \\ Interface \\ Clinical Effects \\ Summary
}

\begin{abstract}
For hypoxemic respiratory failure, the frontline treatment is supplemental oxygen. Since ARDS was first described, mechanical ventilation via an endotracheal tube (invasive ventilation) has no doubt saved many patients. During the 1990s, noninvasive ventilation was found to be superior to invasive ventilation for exacerbations of COPD, acute cardiogenic pulmonary edema, and acute respiratory failure in patients who were immunocompromised. In the 2000s, less invasive high-flow nasal cannula (HFNC) therapy gained attention as an alternative means of respiratory support for patients who were critically ill. The HFNC system is simple: it requires only a flow generator, active heated humidifier, single heated circuit, and nasal cannula. While NIV interfaces add to anatomic dead space, HFNC delivery actually decreases dead space. Although the use of HFNC in adults who are critically ill has been dramatically increasing, the advantages and disadvantages of each element have not been well discussed. For now, although functional differences among the different HFNC systems seem to be minor, to avoid adverse clinical events, it is essential to know the advantages and disadvantages of each element. Key words: humidification; dead space washout; noninvasive ventilation; patient sensation. [Respir Care 2019;64(6):735-742. (C) 2019 Daedalus Enterprises]
\end{abstract}

\section{Introduction}

For hypoxemic respiratory failure, the frontline treatment is supplemental oxygen. In 1967 "acute respiratory distress" was recognized and reported for the first time in the medical literature, ${ }^{1}$ and PEEP was considered to be effective for improving oxygenation. Since then, despite having well-known adverse effects, mechanical ventilation

Dr Nishimura is affiliated with Tokushima Prefuctural Central Hospital, Tokushima, Japan.

Dr Nishimura presented a version of this paper at the 57th RESPIRATORY CARE Journal Conference, Noninvasive Respiratory Support in Adults, held June 14-15, 2018, in St Petersburg, Florida.

The author has disclosed no conflicts of interest. with an endotracheal tube (invasive ventilation) has no doubt saved many patients. During the 1990s, physicians began to prescribe noninvasive ventilation (NIV) to support patients with acute respiratory failure. ${ }^{2}$ Since then, NIV has been found to be superior to invasive ventilation for patients with COPD exacerbations $\mathrm{s}^{3,4}$ and acute cardiogenic pulmonary edema, ${ }^{5}$ in those patients who are immunocompromised and in acute respiratory failure. ${ }^{6-8}$ In the 2000s, high-flow nasal cannula (HFNC) therapy gained attention as an alternative means of respiratory support for

\footnotetext{
Correspondence: Masaji Nishimura MD PhD, Tokushima Prefuctural Central Hospital, 1-10-3 Kuramoto, Tokushima 770-8539, Japan. E-mail: nmasaji@tokushima-u.ac.jp.
}

DOI: $10.4187 /$ respcare .06718 


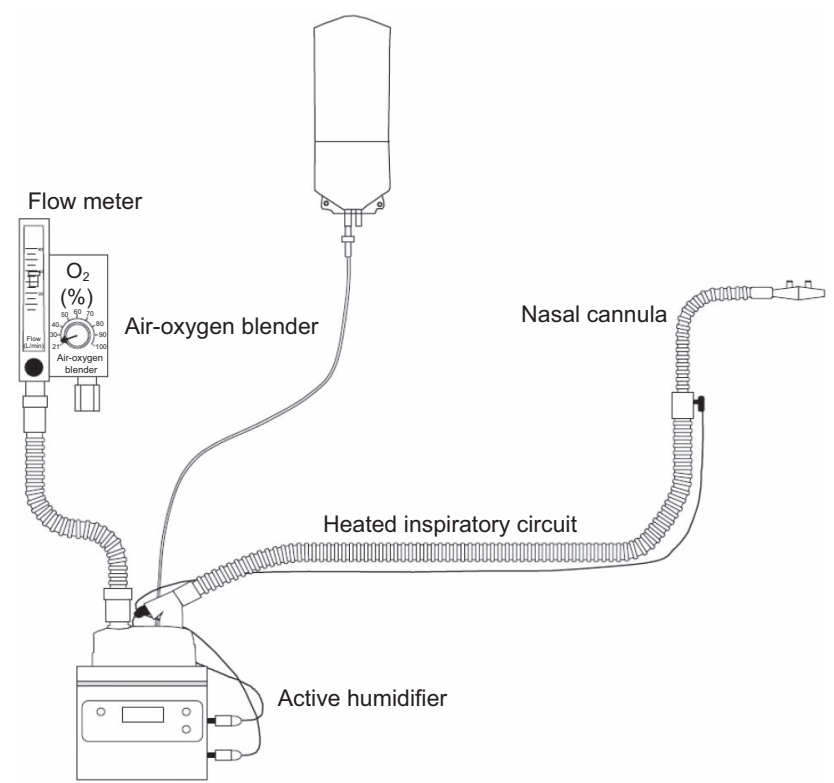

Fig. 1. Basic setup for high-flow nasal cannula oxygen delivery. An air-oxygen blender, which allows $\mathrm{F}_{\mathrm{IO}_{2}}$ from 0.21 to 1.0 , generates up to $60 \mathrm{~L} / \mathrm{min}$ flow. The gas is heated and humidified through an active-heated humidifier and is delivered via a single-limb heated inspiratory circuit. The patient breathes adequately heated and humidified medical gas through large-diameter nasal cannulas. From Reference 9.

patients who were critically ill and was attractive because it was even less invasive. ${ }^{9-12}$ Initially, there was skepticism as to whether it was as good as NIV for treating acute hypoxemic respiratory failure. Analysis of the results of recent clinical trials, however, show that, at least it is not inferior to NIV. ${ }^{13-15}$

A typical HFNC system consists of a flow generator, active heated humidifier, single-limb heated circuit, and nasal cannula. ${ }^{16}$ According to the monitored oxygen concentration, $\mathrm{F}_{\mathrm{IO}_{2}}$ can be titrated with flows up to $60 \mathrm{~L} / \mathrm{min}$. The differences between NIV and HFNC are the interfaces as well as consistent pressure versus the ability to provide different inspiratory and expiratory pressures. Although NIV interfaces add to the anatomic dead space, HFNC delivery actually decreases dead space. ${ }^{17-20}$ Because HFNC is an open system, it does not actively enhance tidal volume; however, it does improve alveolar ventilation by washing out anatomic dead space. ${ }^{18,19}$ The simplicity and excellent patient tolerance of the system is attractive, ${ }^{21}$ and, owing to these advantages, ${ }^{16,22}$ the use of HFNC for adults who are critically ill has been dramatically increasing. HFNC may make it easier to initiate earlier respiratory support, and the device has the potential to decrease the necessity or duration of mechanical ventilation. ${ }^{23}$ As described above, HFNC is a simple system composed of a flow generator, humidifying device, inspiratory limb, and nasal interface (Fig. 1). ${ }^{24}$
Below, the advantages and disadvantages of each element are discussed separately.

\section{Flow Generator}

There are 3 types of standalone flow generators: airoxygen blenders, built-in flow generators, and entrainment systems (Fig. 2). Of these, the air-oxygen blender with flow meter is the most popular. Use of air and oxygen directly from the wall supply, a mechanical air-oxygen blender, and a flow meter enables stable delivery both of $\mathrm{F}_{\mathrm{IO}_{2}}$ and gas flow. In general, air-oxygen blenders titrate oxygen concentration according to the amount of medical gas inhaled; some gas is lost via the blender. Precise flow generators are incorporated into devices manufactured by Fisher \& Paykel Healthcare (Auckland, New Zealand) and Vapotherm (NH). These usually use turbines and entrain room air to generate high flow. High flow can thus be generated even though air and high-pressure oxygen wall supplies are unavailable. These devices monitor delivered oxygen concentration, supplied via a low-pressure system, in the delivered gas. Oxygen loss is negligible, but, with these devices, high concentrations of oxygen are not available. When higher concentrations are necessary, a MaxVenturi (Maxtec, UT) generates high flow through using an air-entrainment system: when equipped with a flow meter, it also titrates oxygen concentration.

Each of these flow generators also generates noise, which increases with flow. Air entrainment in Venturi systems is particularly noisy, and a recent study ${ }^{25}$ found that the noise level was significantly higher with the air entrainment system compared with an air-oxygen blender and flow generator incorporated in AIRVO 2 (Fisher \& Paykel) (Fig. 3). As $\mathrm{F}_{\mathrm{IO}_{2}}$ increases, air entrainment decreases; however, the required rise in oxygen flow to keep the total flow constant also generates more noise. Louder noise increases patient discomfort. Noise is one of the major causes of disturbed sleep and insomnia in the ICU.26,27 As one might expect, increased noise results in unpleasant sensations, and both noise level and sound elements seem related to this effect (Fig. 4). In a number of critical care ventilators, a HFNC capability is integral to the machine. In these cases, the ventilator allows control of $\mathrm{F}_{\mathrm{IO}_{2}}$ and flow while using the heated humidifier commonly connected to the ventilator. WHile these systems have become more common, in most instances a stand-alone system is used. HFNC in a ventilator may allow easy application post-extubation, using the ventilator previoulsy providing ventilatory support without additional hardware.

\section{Humidifying Devices}

Dry gas is known to have diverse adverse effects on the respiratory system, such as mucociliary malfunction, epi- 

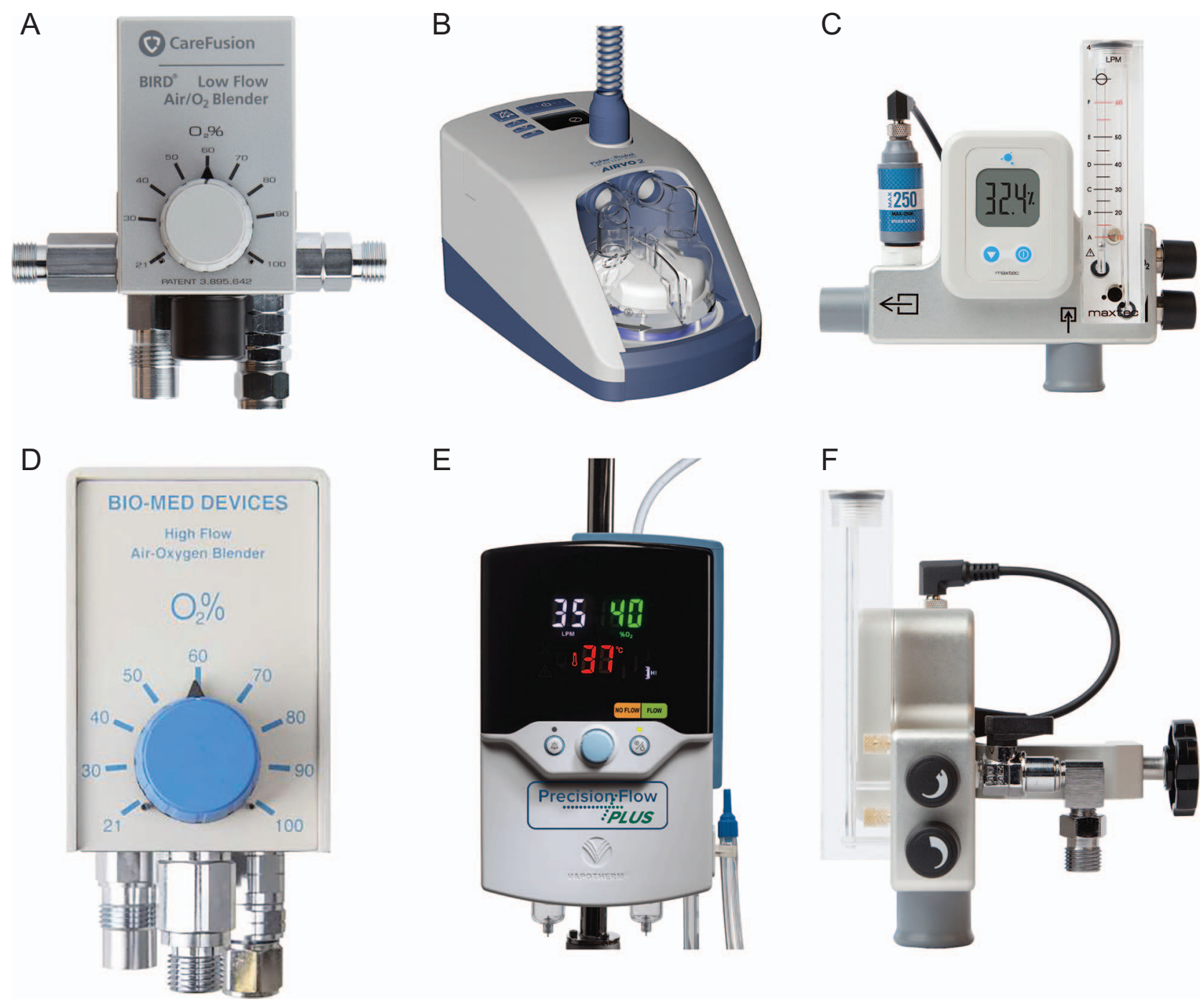

Fig. 2. There are 3 types of flow generators: air-oxygen blenders, turbines, and Venturi. Air-oxygen blender with a flow meter is the most common. By using a mechanical air-oxygen blender and flow meter, oxygen concentration and flows are stable (A: Bird blender (Vyaire Medical, IL) and D: Air-oxgen blender (Bio-Med Devices, CT) ). B: A flow generator is built in with the AIRVO 2 Fisher \& Paykel Healthcare (Auckland, New Zealand). E: Precision Flow Plus (Vapotherm, NH). Oxygen is supplied via a low-pressure system, while the device monitors oxygen concentration. C and F: The MaxVenturi (Maxtec, UT) uses a flow generator to create high flow by Venturi. It is composed of a flow meter and oxygen concentration monitor. Noise is an important consideration. Courtesy Maxtec, Fisher \& Paykel Healthcare, Bio-Med Devices, and Vapotherm.

thelial damage, mucus plugging, ulceration of mucosa, and lung injury. ${ }^{28,29}$ At flows of up to $60 \mathrm{~L} / \mathrm{min}$, HFNC delivers medical gas, usually through a heated humidifier incorporated into the delivery system. Vapotherm provides a filter-type humidifying system. Humidification is generated by passing blended gas through a bundle of narrow tubes (similar to a fluid warmer for IV fluids) with $0.005 \mu$ pore size. Compared with pass-over heated humidifying systems, filter systems require a large evaporative surface. Vapotherm supplies 2 cartridge sizes: one for flows of 5-40 L/min and the other for flows of $1-8 \mathrm{~L} / \mathrm{min}$. Both pass-over and filter-cartridge humidifying devices usually work well, ${ }^{30-32}$ and humidifying performance is adequate un- til flow exceeds $60 \mathrm{~L} / \mathrm{min}^{9}{ }^{9,33}$ Humidifying performance depends on the patient: during spontaneous breathing, tidal volume and inspiratory flow vary both individually and breath by breath. ${ }^{34,35}$ When HFNC flow is less than the inspiratory flow, the patient also inspires ambient air that contains less humidity (Fig. 5).

\section{Inspiratory Limb}

Even with the best heated humidifiers, some vapor is lost as condensation in the inspiratory circuit. ${ }^{36,37}$ To ensure delivery of adequately humidified medical gas to patients, it is important to avoid circuit vapor loss. With 
aiming to minimize condensation, manufacturers have developed various types of inspiratory circuits, of which, the most widely adopted type is a circuit that simply contains a heating wire. The heated-wire circuit is also often chosen in invasive and noninvasive respiratory support. To regulate the thermal output of the heating wire placed inside the limb, the supplied electric current is servo-controlled. Heating-wire placement differs, depending on the maker (RT202 [Fisher \& Paykel] and SLH [Intersurgical, Berkshire, United Kingdom]) (Fig. 6). SLH has only a short

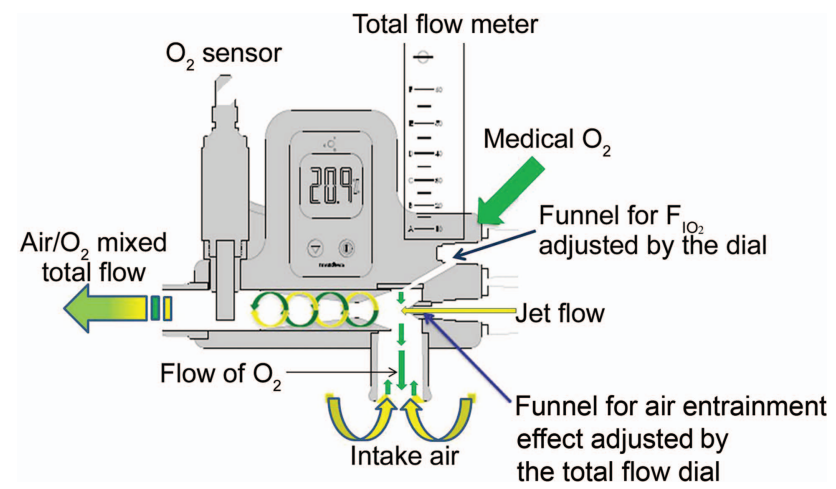

Fig. 3. Structure of MaxVenturi. High flow is generated through air entrainment constriction; equipped with a flow meter and oxygen analyzer. Jet flow creates negative pressure around itself. Flow is titrated by adjusting jet flow outlet. The higher the flow, the greater the negative pressure and amount of entrained air. Jet flow is noisy. From Reference 25. heating wire, and the distal end of the wire and the location of the temperature probe is different from the RT202. Although only $10 \mathrm{~cm}$ long, the wire influences temperature control and decreases condensation; however, because of the temperature gradient from each of the heating wires to the circuit wall, some degree of condensation is inevitable and is likely to be greater with a shorter wire. Placing a plastic sleeve around the circuit can insulate the limb exterior from cooler ambient air and decrease condensation. ${ }^{36}$ More sophisticated circuits have recently been developed. For example, use of heating wires embedded in the circuit wall keeps the wall temperature high enough to avoid condensation (Fig. 6). ${ }^{38}$

Vapotherm devised a distinctive coaxial design. Rather than using a heating wire inside the circuit, warm water runs between the inner and outer lumens of the tubes through which medical gas is delivered. This system prevents cooling from ambient air and decreases the amount of condensation in the inspiratory circuit. ${ }^{39}$ It is an application of almost identical systems that are used for warming blood or infusion fluids (Fig. 7).

Beyond the circuit, condensation may also accumulate in the nasal prongs, which results in water droplet spray into the nostrils. Besides disturbing sleep, this rainout may induce coughing and desaturation. The lower the ambient temperature, the more likely there is to be condensation. In addition to discomfort and possible clinically important

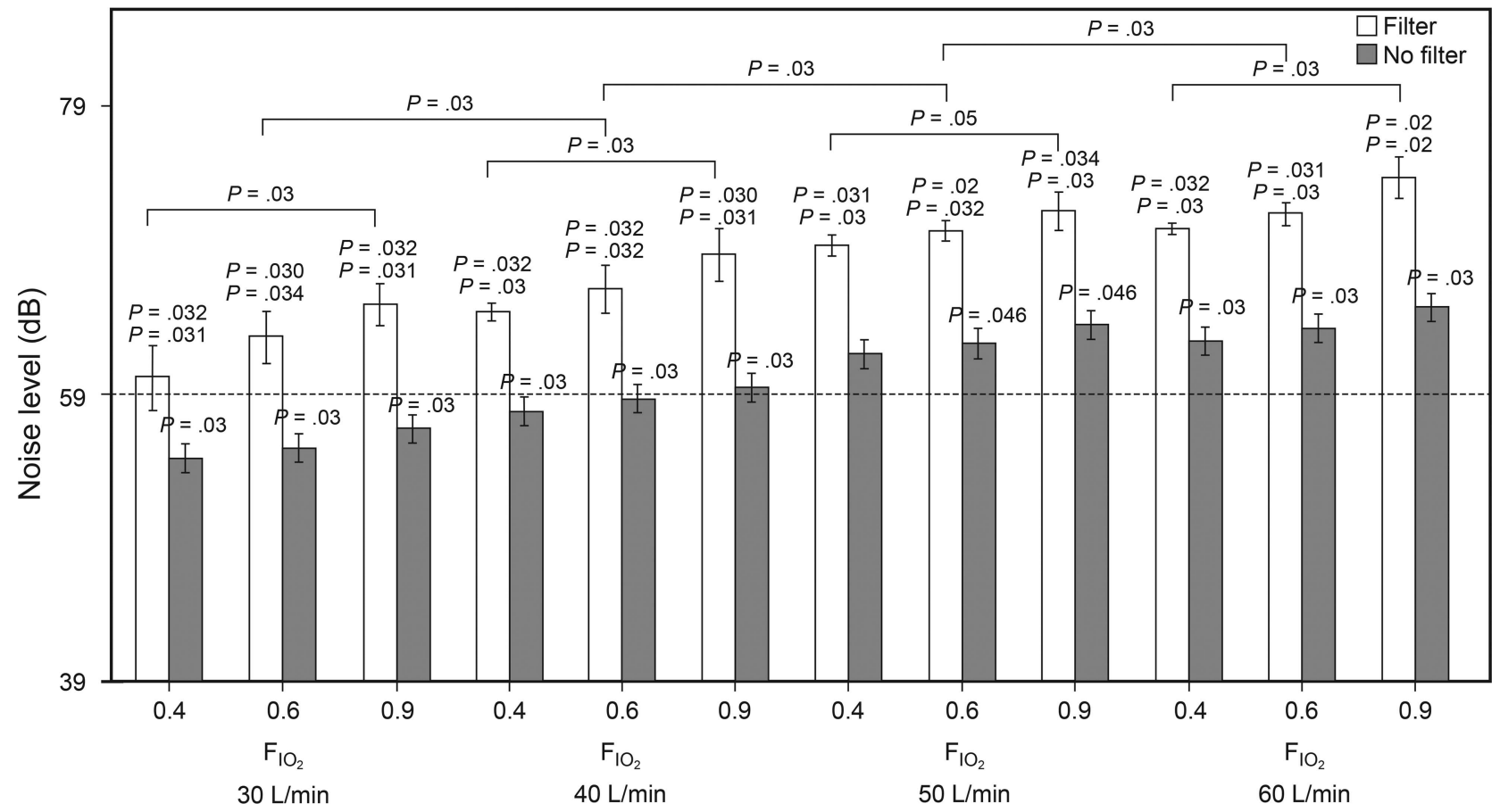

Fig. 4. Noise levels of high-flow nasal cannula (HFNC) systems (OptiFlow, MaxVenturi, and AIRVO 2). Here only the noise level of the MaxVenturi was presented. The noise level of the MaxVenturi was loudest among the systems, regardless of settings. As flow increased, noise level got louder. The $y$-axis shows noise level $(\mathrm{dB})$ and $\mathrm{x}$-axis displays settings $\left(\right.$ flow $/ \mathrm{F}_{\mathrm{IO}_{2}}$ ). From Reference 25. 

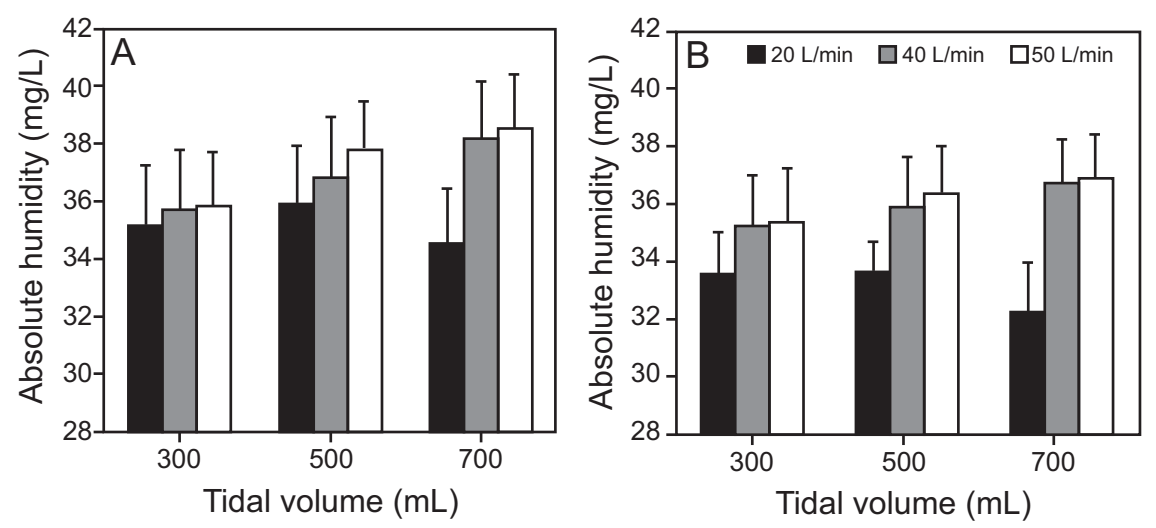

Fig. 5. Effects of flow and tidal volume $\left(\mathrm{V}_{\mathrm{T}}\right)$ on absolute humidity. At high-flow nasal cannula (HFNC) flow of $20 \mathrm{~L} / \mathrm{min}$, when $\mathrm{V}_{\mathrm{T}}$ increased from 300 to $700 \mathrm{~mL}$, absolute humidity decreased; at HFNC flow of 40 and $50 \mathrm{~L} / \mathrm{min}$, absolute humidity did not vary according to $\mathrm{V}_{\mathrm{T}}$. A: AIRVO 2. B: Optiflow. Both AIRVO 2 and Optiflow delivered appropriate levels of absolute humidity, except at 20 L/min with Optiflow.

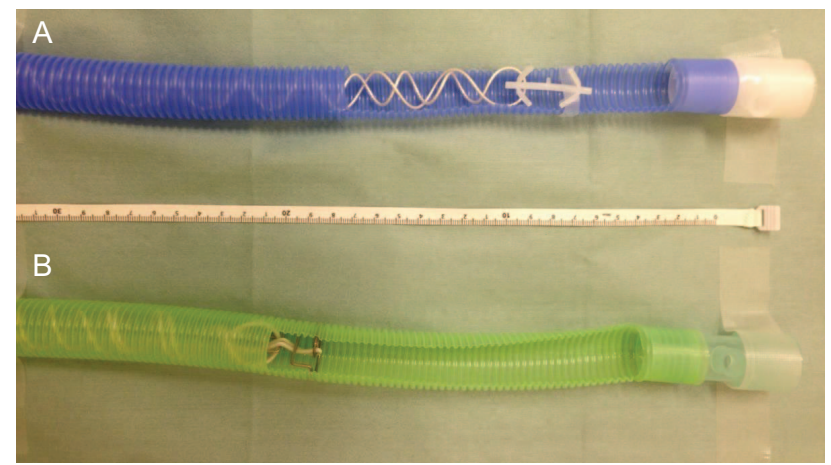

Fig. 6. Distance between the end of heating wire and temperature probe differs between circuits. In this example, it is $\sim 10 \mathrm{~cm}$; however, this can influence temperature control and the amount of condensation. A: RT202. B: SLH.

worsening of the patient's condition, condensation increases the incidence of patient arousal, aspiration, irritation, and desaturation. The sequelae from these effects may need to be factored into the health-care provider's workflow, especially for respiratory therapists and nurses. ${ }^{39}$

\section{Interface}

During the past 2 decades, increasing utilization of NIV has been important in the field of respiratory support. ${ }^{5-8,40-46}$ No studies, however, reported a $100 \%$ success rate. ${ }^{42,47}$ One major reason for this is patient discomfort or intolerance of interfaces. Oronasal masks are usually tried first, but many patients find them too uncomfortable to tolerate. HFNC is reportedly better tolerated by patients than is NIV. ${ }^{9}$

The high-velocity nasal insufflation system (Hi-VNI, Vapotherm) uses a slender nasal cannula similar in appearance to a regular nasal oxygen cannula. Both the in- ternal diameter and nasal prong bore are narrow, and this results in high flow out of the nasal prongs. ${ }^{17}$ Moreover, via 2 connecting tubes, Hi-VNI delivers flow to each prong from either side. By contrast, with the Optiflow system (Fisher \& Paykel), the nasal prongs and tubing between the nasal prong and inspiratory circuit are both large bore, and flow to the prongs is delivered from one side only (Fig. 8). A computational fluid dynamics study in a model set for flow of $20 \mathrm{~L} / \mathrm{min}$ found greater flow velocity in the vortices from the smaller prong cannulas and additional anterior vortices on each side of the nasal septum. ${ }^{17}$ The anatomy of the nasal cavity of humans is more complex, however, and it remains unclear how relevant this model is to real-life physiology.

\section{Clinical Effect}

Few studies have compared the clinical effects of HFNC devices. In preterm infants, Mahoney et al ${ }^{48}$ compared the Vapotherm and Optiflow devices for weaning from nasal CPAP and found that both were similarly effective for weaning without increasing the risk of pneumothorax or bronchopulmonary dysplasia. Tero et $\mathrm{al}^{39}$ compared the workflow with conventional humidifiers and integrated HFNC systems in a neonatal ICU. Regardless of scheduled or unscheduled, staff contacts for tasks such as clearing circuit water was statistically and significantly less with integrated HFNC systems. With conventional humidifiers, clinical event incidences, patient arousal, crying, and desaturation were higher. However, pediatric studies do not necessarily translate to adult patients.

\section{Summary}

HFNC is a simple system with clinical effects mainly dependent on flow, oxygen concentration, and temperature 


\section{HFNC DEVICES}
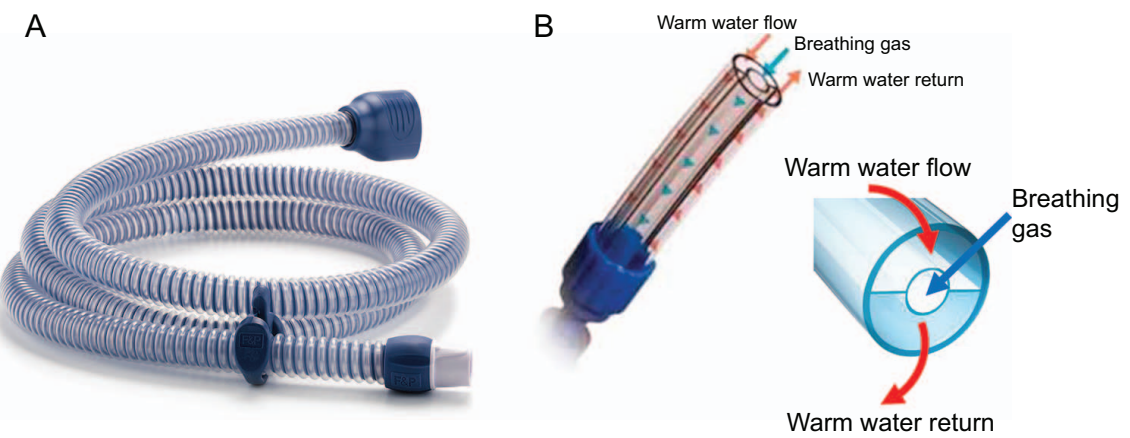

Cross-section of tubing

Fig. 7. A: The AirSpiral (Fisher \& Paykel) breathing tube uses heating wires embedded in the circuit wall to keep wall temperature high enough to avoid condensation. B: Distinctive coaxial (Vapotherm). Rather than using a heating wire inside the limb, warm water runs between the outer lumen and inner lumen through which medical gas is delivered. Images courtesy Fisher \& Paykel Healthcare and Vapotherm.
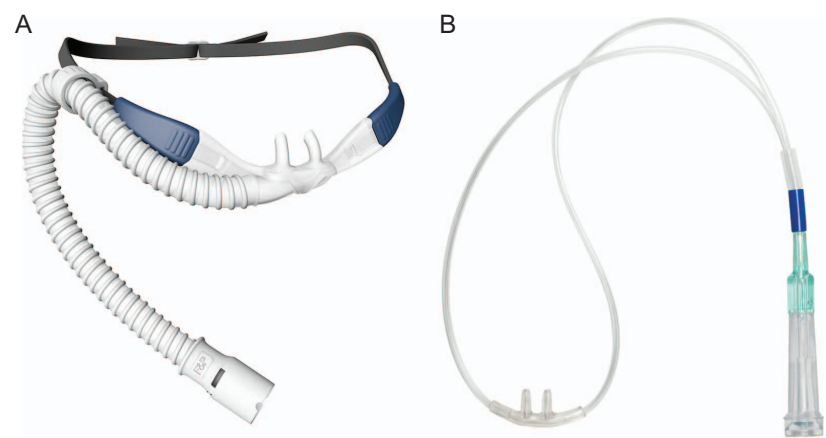

Fig. 8. A: Optiflow nasal prongs and inspiratory circuit are both large bore. Flow is delivered from one side only. B: The high-velocity nasal insufflation (Hi-VNI) system (Vapotherm) uses a slender nasal cannula similar in appearance to a regular nasal oxygen cannula. Images courtesy Fisher \& Paykel Healthcare and Vapotherm.

setting. Usually, end-inspiratory lung volume increases as flow increases. ${ }^{49}$ Greater flow also washes out more anatomic dead space. ${ }^{18,19}$ For patients with acute hypoxemic respiratory failure, the HFNC gas temperature may affect comfort: at equal flows, there is evidence that lowering the temperature to $31^{\circ} \mathrm{C}$ can be more comfortable than $37^{\circ} \mathrm{C} .4^{4}$ Patients with more-severe hypoxemia find higher flows more comfortable. Although the functional differences between various HFNC systems are minor, it is essential to prevent rainout in the inspiratory circuit to avoid adverse clinical events. Another HFNC issue in the clinical setting is noise. This needs to be successfully addressed to provide optimal care for patients.

\section{REFERENCES}

1. Ashbaugh DG, Bigelow DB, Petty TL, Levine BE. Acute respiratory distress in adults. Lancet 1967;2(7511):319-323.

2. Brochard L, Mancebo J, Wysocki M, Lofaso F, Conti G, Rauss A, et al. Noninvasive ventilation for acute exacerbations of chronic obstructive pulmonary disease. N Engl J Med 1995;333(13):817822.
3. Brochard L, Isabey D, Piquet J, Amaro P, Mancebo J, Messadi AA, et al. Reversal of acute exacerbations of chronic obstructive lung disease by inspiratory assistance with a face mask. N Engl J Med 1990;323(22):1523-1530.

4. Chandra D, Stamm JA, Taylor B, Ramos RM, Satterwhite L, Krishnan JA, et al. Outcomes of noninvasive ventilation for acute exacerbations of chronic obstructive pulmonary disease in the United States, 1998-2008. Am J Respir Crit Care Med 2012;185(2):152159.

5. Gray A, Goodacre S, Newby DE, Masson M, Sampson F, Nicholl J. Noninvasive ventilation in acute cardiogenic pulmonary edema. N Engl J Med 2008;359(2):142-151.

6. Lemiale V, Mokart D, Resche-Rigon M, Pène F, Mayaux J, Faucher E, et al.; Groupe de Recherche en Réanimation Respiratoire du patient d'Onco-Hématologie (GRRR-OH)). Effect of noninvasive ventilation vs oxygen therapy on mortality among immunocompromised patients with acute respiratory failure: a randomized clinical trial. JAMA 2015;314(16):1711-1719.

7. Wang T, Zhang L, Luo K, He J, Ma Y, Li Z, et al. Noninvasive versus invasive mechanical ventilation for immunocompromised patients with acute respiratory failure: a systematic review and metaanalysis. BMC Pulm Med 2016;16(1):129.

8. Hilbert G, Gruson D, Vargas F, Valentino R, Gbikpi-Benissan G, Dupon $\mathrm{M}$, et al. Noninvasive ventilation in immunosuppressed patients with pulmonary infiltrates, fever, and acute respiratory failure. N Engl J Med 2001;344(7):481-487.

9. Calvano TP, Sill JM, Kemp KR, Chung KK. Use of a high-flow oxygen delivery system in a critically ill patient with dementia. Respir Care 2008;53(12):1739-1743.

10. Parke R, McGuinness S, Eccleston M. Nasal high-flow therapy delivers low level positive airway pressure. Br J Anaesth 2009;103(6): 886-890.

11. Boyer A, Vargas F, Delacre M, Saint-Léger M, Clouzeau B, Hilbert G, Gruson D. Prognostic impact of high-flow nasal cannula oxygen supply in an ICU patient with pulmonary fibrosis complicated by acute respiratory failure. Intensive Care Med 2011; 37(3):558-559.

12. Carratalá Perales JM, Llorens $P$, Brouzet B, Albert Jiménez AR, Fernández-Cañadas JM, Carbajosa Dalmau J, et al. High-flow therapy via nasal cannula in acute heart failure. Rev Esp Cardiol 2011; 64(8):723-725.

13. Frat JP, Ragot S, Girault C, Perbet S, Prat G, Boulain T, et al.; REVA network. Effect of non-invasive oxygenation strategies in immunocompromised patients with severe acute respiratory failure: a post- 
hoc analysis of a randomised trial. Lancet Respir Med 2016;4(8): 646-652.

14. Hernández G, Vaquero C, Colinas L, Cuena R, González P, Canabal A, et al. Effect of postextubation high-flow nasal cannula vs noninvasive ventilation on reintubation and postextubation respiratory failure in high-risk patients: a randomized clinical trial. JAMA 2016; 316(15):1565-1574

15. Frat JP, Thille AW, Mercat A, Girault C, Ragot S, Perbet S, et al.; FLORALI Study Group, REVA Network. High-flow oxygen through nasal cannula in acute hypoxemic respiratory failure. N Engl J Med 2015;372(23):2185-2196

16. Nishimura M. High-flow nasal cannula oxygen therapy in adults: physiological benefits, indication, clinical benefits, and adverse effects. Respir Care 2016;61(4):529-541.

17. Miller TL, Saberi B, Saberi S. Computational fluid dynamics modeling of extrathracic airway flush: evaluation of high flow cannula design elements. J Pulm Respir Med 2016;6(5).

18. Möller W, Celik G, Feng S, Bartenstein P, Meyer G, Oliver E, et al. Nasal high flow clears anatomical dead space in upper airway models. J Appl Physiol (1985) 2015;118(12):1525-1532.

19. Möller W, Feng S, Domanski U, Franke KJ, Celik G, Bartenstein P, et al. Nasal high flow reduces dead space. J Appl Physiol (1985) 2017;122(1):191-197.

20. Wettstein RB, Shelledy DC, Peters JI. Delivered oxygen concentrations using low-flow and high-flow nasal cannulas. Respir Care 2005; 50(5):604-609.

21. Spoletini G, Alotaibi M, Blasi F, Hill NS. Heated humidified highflow nasal oxygen in adults: mechanisms of action and clinical implications. Chest 2015;148(1):253-261.

22. Mauri T, Turrini C, Eronia N, Grasselli G, Volta CA, Bellani G, Pesenti A. Physiologic effects of high-flow nasal cannula in acute hypoxemic respiratory failure. Am J Respir Crit Care Med 2017; 195(9):1207-1215.

23. Nagata K, Morimoto T, Fujimoto D, Otoshi T, Nakagawa A, Otsuka $\mathrm{K}$, et al. Efficacy of high-flow nasal cannula therapy in acute hypoxemic respiratory failure: decreased use of mechanical ventilation. Respir Care 2015;60(10):1390-1396.

24. Nishimura M. High-flow nasal cannula oxygen therapy in adults. J Intensive Care 2015;3(1):15.

25. Kubo T, Nakajima H, Shimoda R, Seo T, Kanno Y, Kondo T, Tamai S. Noise exposure from high-flow nasal cannula oxygen therapy: a bench study on noise reduction. Respir Care 2018;63(3):267-273.

26. Hu RF, Jiang XY, Hegadoren KM, Zhang YH. Effects of earplugs and eye masks combined with relaxing music on sleep, melatonin and cortisol levels in ICU patients: a randomized controlled trial. Crit Care 2015;19:115.

27. Pulak LM, Jensen L. Sleep in the intensive care unit: a review. J Intensive Care Med 2016;31(1):14-23.

28. Chidekel A, Zhu Y, Wang J, Mosko JJ, Rodriguez E, Shaffer TH. The effects of gas humidification with high-flow nasal cannula on cultured human airway epithelial cells. Pulm Med 2012;2012:380686.

29. Hirsch JA, Tokayer JL, Robinson MJ, Sackner MA. Effects of dry air and subsequent humidification on tracheal mucous velocity in dogs. J Appl Physiol 1975;39(2):242-246.

30. Chikata Y, Izawa M, Okuda N, Itagaki T, Nakataki E, Onodera M, et al. Humidification performance of two high-flow nasal cannula devices: a bench study. Respir Care 2014;59(8):1186-1190.

31. Chikata Y, Ohnishi S, Nishimura M. Humidity and inspired oxygen concentration during high-flow nasal cannula therapy in neonatal and infant lung models. Respir Care 2017;62(5):532-537.

32. Chikata Y, Oto J, Onodera M, Nishimura M. Humidification performance of humidifying devices for tracheostomized patients with spontaneous breathing: a bench study. Respir Care 2013; 58(9): $1442-1448$
33. McQueen M, Rojas J, Sun SC, Tero R, Ives K, Bednarek F, et al Safety and long term outcomes with high flow nasal cannula therapy in neonatology: a large retrospective cohort study. J Pulm Respir Med 2014;4(6). pii: 216

34. Tobin MJ, Mador MJ, Guenther SM, Lodato RF, Sackner MA. Variability of resting respiratory drive and timing in healthy subjects. J Appl Physiol (1985) 1988;65(1):309-317.

35. Askanazi J, Silverberg PA, Hyman AI, Rosenbaum SH, Foster R, Kinney JM. Patterns of ventilation in postoperative and acutely ill patients. Crit Care Med 1979;7(2):41-46.

36. Chikata Y, Unai K, Izawa M, Okuda N, Oto J, Nishimura M. Inspiratory tube condensation during high-flow nasal cannula therapy: a bench study. Respir Care 2016;61(3):300-305.

37. Chikata Y, Imanaka H, Onishi Y, Ueta M, Nishimura M. Humidification during high-frequency oscillation ventilation is affected by ventilator circuit and ventilatory setting. Paediatr Anaesth 2009;19(8): 779-783.

38. Fisher \& Paykel Healthcare. AirSpiral breathing tube. https://www. fphcare.com/nz/products/airvo-2-airspiral-tube/. Accessed April 16, 2019.

39. Tero R, Cecich J, Sanabria O, Sun S, Batista J, Stout S, et al. Risks associated with conventional humidifiers adapted for high-flow nasal cannula therapy in human infants: results of a time and motion study. Int J Clin Pediatr 2014;3(4):99-104.

40. Esteban A, Frutos-Vivar F, Ferguson ND, Arabi Y, Apezteguía C, González M, et al. Noninvasive positive-pressure ventilation for respiratory failure after extubation. N Engl J Med 2004;350(24):24522460

41. Lemiale V, Mokart D, Azoulay E; Groupe de Recherche en Réanimation Respiratoire Onco-Hématologique (GRRR-OH). Noninvasive ventilation and outcomes among immunocompromised patientsReply. JAMA 2016;315(17):1902-1903.

42. Ozyilmaz E, Ugurlu AO, Nava S. Timing of noninvasive ventilation failure: causes, risk factors, and potential remedies. BMC Pulm Med 2014; $14: 19$

43. Baillard C, Fosse JP, Sebbane M, Chanques G, Vincent F, Courouble $\mathrm{P}$, et al. Noninvasive ventilation improves preoxygenation before intubation of hypoxic patients. Am J Respir Crit Care Med 2006; 174(2):171-177.

44. Köhnlein T, Windisch W, Köhler D, Drabik A, Geiseler J, Hartl S, et al. Non-invasive positive pressure ventilation for the treatment of severe stable chronic obstructive pulmonary disease: a prospective, multicentre, randomised, controlled clinical trial. Lancet Respir Med 2014;2(9):698-705.

45. Rialp Cervera G, del Castillo Blanco A, Pérez Aizcorreta O, Parra Morais L, GT-IRA of SEMICYUC. Noninvasive mechanical ventilation in chronic obstructive pulmonary disease and in acute cardiogenic pulmonary edema. Med Intensiva 2014;38(2):111-121.

46. Patel BK, Wolfe KS, Pohlman AS, Hall JB, Kress JP. Effect of noninvasive ventilation delivered by helmet vs face mask on the rate of endotracheal intubation in patients with acute respiratory distress syndrome: a randomized clinical trial. JAMA 2016;315(22):2435-2441.

47. Adda M, Coquet I, Darmon M, Thiery G, Schlemmer B, Azoulay E. Predictors of noninvasive ventilation failure in patients with hematologic malignancy and acute respiratory failure. Crit Care Med 2008; 36(10):2766-2772.

48. Mahoney L, Fernandez Alvarez JR, Gandhi R, Bomont R, Garland $\mathrm{C}$, Rabe H. Optiflow versus Vapotherm as extended weaning mode from nasal continuous airway pressure in preterm infants $<28$ weeks gestational age. Pediatr Res 2011;70:526.

49. Mauri T, Galazzi A, Binda F, Masciopinto L, Corcione N, Carlesso E, et al. Impact of flow and temperature on patient comfort during respiratory support by high-flow nasal cannula. Crit Care 2018;22(1):120. 


\section{Discussion}

Strickland: I have a quick question. One of the last items you talked about was that a lower temperature may be more comfortable for the patient but that we also have to balance that with using an appropriate temperature that carries the right amount of humidity to the patient. Is one more important than the other?

Nishimura: In our ICU, we usually set it to $37^{\circ} \mathrm{C}$, mainly because most of our patients accept that setting. But in this study, ${ }^{1}$ the authors more subjects preferred the lower temperature. The subjects would accept $37^{\circ} \mathrm{C}$ but the authors only compared comfort. I prefer to use $37^{\circ} \mathrm{C}$.

\footnotetext{
* Julie A Jackson RRT RRT-ACCS, invited discussant, Fisher \& Paykel.
}

* Jackson: To add to Shawna's question, my experience has been that, if they are patients with COPD, they tend to like a lower humidity level. They complain a lot more that it's too hot-that might just be the patients with COPD because they're the ones who like fans blowing and air moving in the room. That's really the only patient population I've seen that complains about the heat being too hot, and we'll turn it down for them a little bit. We always start at $37^{\circ} \mathrm{C}$ because it's our normal body temperature and it's what our cilia in our airway require to be able to function properly. That's what we've seen initially.

Piraino: I think your observation is important because we have these humid summers with weather warnings for people with chronic respiratory disease not to go outside. So they likely are more sensitive in terms of dyspnea when the temperature is very hot.
Perhaps temperature is more patient specific, and, again, it all comes back to perhaps we should interact more with our patients to say "does this feel too hot?" Most devices have the option to choose lower temperatures, they may not be the ideal temperature, but it's what the patient would prefer. Tolerance of therapy is by all means most important.

Volsko: Although I don't deal with patients with COPD, we've found that same phenomenon with our patients with cystic fibrosis, especially the adult patients and those with a greater disease severity. The patients were much more comfortable when we turned down the temperature on the heated high-flow nasal cannula.

\section{REFERENCE}

1. Mauri T, Galazzi A, Binda F, Masciopinto L, Corcione N, Carlesso E et al. Impact of flow and temperature on patient comfort during respiratory support by high-flow nasal cannula. Crit Care 2018;221:120. 